\title{
Nicotine-induced upregulation of antioxidant protein Prx 1 in oral squamous cell carcinoma
}

\author{
ZHAO YanHua ${ }^{1}$, ZHANG Min $^{1}$, YAN Fei $^{2}$, CASTO Bruce $\mathrm{C}^{3} \&$ TANG XiaoFei ${ }^{1 *}$ \\ ${ }^{1}$ Division of Oral Pathology, Beijing Institute of Dental Research, School of Stomatology, Capital Medical University, Beijing 100050, China; \\ ${ }^{2}$ Division of Medical Oncology, Department of Internal Medicine, Ohio State University College of Medicine and Comprehensive Cancer Center, \\ Columbus, $\mathrm{OH} 43210$, USA, \\ ${ }^{3}$ Division of Environmental Health Sciences, Ohio State University College of Public Health, Columbus, OH 43210, USA
}

Received November 29, 2012; accepted January 8, 2013; published online March 26, 2013

\begin{abstract}
Nicotine is a source of exogenous oxidative stress, which is associated with the pathogenesis of numerous diseases including oral squamous cell carcinoma (OSCC), whereas an antioxidant protein, peroxiredoxin 1 (Prx 1), plays an important role in the modulation of this condition. This study was to investigate the association between Prx 1 and tobacco-induced oxidative stress. The expression of Prx 1 and GST $\pi$ in OSCC Tca8113 cells, which were pre-treated with nicotine, was determined. In the present study, MTT assay, reactive oxygen species (ROS) assay, RT-PCR and Western blot analyses, respectively, were conducted to assess cell viability, ROS level, and expression level of $\operatorname{Prx} 1$ and GST $\pi$ in nicotine-treated Tca8113 cells. Nuclear factor kappa B (NF-кB) expression was detected by immuno-fluorescence. Our results showed the growth of Tca8113 cells was increased in a dose-dependent manner when cells were treated with nicotine at concentrations from 0.1 to $10 \mu \mathrm{mol} / \mathrm{L}$, but the proliferation of the cells decreased at $100 \mu \mathrm{mol} / \mathrm{L}$. ROS levels increased in all groups treated with nicotine at concentrations of $0.1,1,10$, or $100 \mu \mathrm{mol} / \mathrm{L}$ for $24 \mathrm{~h}$. Prx 1 and GST $\pi$ mRNA and protein expression were up-regulated in cells treated with nicotine for the same time at different concentrations or at the same concentration for different times $(P<0.05)$. NF- $\mathrm{kB}$ was translocated from cytoplasm to nucleus, the expression of NF- $\mathrm{KB}$ was increased in nucleus. These results suggest that up-regulation of Prx1 expression appears to be associated with tobacco-induced oxidative stress, which may play an important role in the pathogenesis of OSCC.
\end{abstract}

Prx1, nicotine, oxidative stress, oral squamous cell carcinoma

Citation: Zhao Y H, Zhang M, Yan F, et al. Nicotine-induced upregulation of antioxidant protein Prx 1 in oral squamous cell carcinoma. Chin Sci Bull, 2013, 58: 1912-1918, doi: 10.1007/s11434-013-5779-1

Oral squamous cell carcinoma (OSCC) is one of the most common malignant neoplasms worldwide [1]. The annual death toll for OSCC has increased rapidly, which may be due to the fact that most OSCC cases are diagnosed at a later stage presumably due to the lack of reliable early diagnostic markers [2]. Detection of OSCC is presently based on clinical examination and subsequent histological analysis of suspicious biopsies, but some minor lesions may be undetectable in hidden sites. Therefore, identification of sensitive and specific biomarkers for OSCC could be helpful for early diagnosis and serve as a screening method in high-risk populations [3].

*Corresponding author (email: xftang10@yahoo.com)
Risk factors for OSCC include tobacco use, alcohol consumption, nutritional deficiency, marijuana use, and exposure to human papilloma and Epstein-Barr viruses. Among all OSCC cases, about $75 \%$ of cases are linked with tobacco use and alcohol consumption, tobacco, by far, is the major risk factor for OSCC $[4,5]$. Nicotine is one of the most important components in tobacco, which increases the levels of reactive oxygen species (ROS) in both oral normal mucosal and cancer epithelial cells [6,7]. Excess ROS induces oxidative stress, cellular damage, and ultimately, malignant transformation.

Peroxiredoxins (Prx, E.C. 1.11.1.15) are thiol-dependent antioxidant proteins. They are found in a wide variety of species and play a critical role in peroxide detoxification [8]. 
Prx 1 is a multifunctional 2-Cys peroxiredoxin family member and is overly expressed in numerous cancers including OSCC [9-11]. However, Prx 1 expression and tobacco-induced oxidative stress have not been elucidated in OSCC. GST $\pi$ is a marker protein in many cancers and high levels are linked to drug resistance. S-glutathionylation of proteins is critical to cellular stress response and GST $\pi$ potentiates S-glutathionylation reactions following oxidative stress in vitro and in vivo. GST $\pi$ could conjugate glutathione to a member of the peroxiredoxin family, including Prx 1 [12].

In our previous investigations, we found that Prx1 and GST $\pi$ both were up-regulated in the OSCC cell line, Tca8113, when compared to the oral precancerous cell line, DOK, by DNA microarray [13]. We hypothesized that nicotine treatment would influence cell proliferation, ROS levels, and Prx1 and GST $\pi$ expression in an OSCC cell line (Tca8113). In the current study, we evaluated these biomarkers in a nicotine-induced OSCC.

\section{Materials and methods}

\subsection{Cell culture}

The Tca8113 human OSCC cell line was obtained from the School of Stomatology, Peking University, Beijing, China. Cells were cultured in RPMI1640 supplemented with $10 \%$ FBS, 100 units $/ \mathrm{mL}$ penicillin, and $100 \mu \mathrm{g} / \mathrm{mL}$ streptomycin at $37^{\circ} \mathrm{C}$, in a $5 \% \mathrm{CO}_{2}$ humidified chamber.

\subsection{MTT assay}

$2.5 \times 10^{4}$ cells were seeded in a 96-well plate and incubated overnight for cell attachment. Cells were treated with $0.1,1$, 10 or $100 \mu \mathrm{mol} / \mathrm{L}$ nicotine (Wako, Japan) for 24,48 or $72 \mathrm{~h}$. After treatment, $20 \mu \mathrm{L}$ of MTT solution $(5 \mathrm{mg} / \mathrm{mL}$ in PBS) (MTT, Sigma, USA) were added to each well and incubated for $4 \mathrm{~h}$. The medium was removed and $150 \mu \mathrm{L}$ DMSO was added to each well. The formazan dye crystals were solubilized for $10 \mathrm{~min}$, and absorbance was then measured by colorimetric assay (TECAN, Austria). The MTT assay was based on the cleavage of the yellow tetrazolium salt MTT to purple formazan crystal by metabolically active cells. The formazan was then solubilized, and the concentration was determined by optical density at $570 \mathrm{~nm}$ [14].

\subsection{ROS assay}

ROS was measured by a cell-permeable fluorogenic probe 2,7-dichlorfluorescein-diacetate (DCFH-DA) described by Rajendra et al. [15]. Briefly, Tca8113 cells $\left(1 \times 10^{5}\right)$ were treated with nicotine $(0.1,1,10,100 \mu \mathrm{mol} / \mathrm{L})$ for $24 \mathrm{~h}$ in a 24 well plate. Then, $2.5 \mu \mathrm{mol} / \mathrm{L}$ DCFH-DA (Puli Lai Company, China) was added to each well and incubated for 30 min. DCFH-DA was diffused into cells and deacetylated by cellular esterases to nonfluorescent 2,7-dichlorodihydrofluorescin (DCFH), which was rapidly oxidized to highly fluorescent 2,7-dichlorodihydrofluorescein (DCF) by ROS. The samples were analyzed by flow cytometry (Coulter Epics@XL, Beckman, USA) in three separate experiments using excitation and emission wavelengths of $480 \mathrm{~nm}$ and $530 \mathrm{~nm}$, respectively.

\subsection{RT-PCR analysis}

Tca8113 cell lines were treated with $0.1,1,10$ or 100 $\mu \mathrm{mol} / \mathrm{L}$ nicotine for $48 \mathrm{~h}$, or $1 \mu \mathrm{mol} / \mathrm{L}$ for 24,48 or $72 \mathrm{~h}$. Total RNA was extracted using TRIzol Reagent (Promega, USA) from nicotine-untreated and nicotine-treated cells according to the manufacturer's instructions. RT-PCR was then performed as previously described [16]. The sequences of primers were as follows: Prx 1: Sense: 5'-ATGTCTTCAGGAAATGCTAAAAT-3', antisense: 5'-TCACTTCTGCTTGGAGAAATATTC-3'; GST $\pi$ : Sense: 5'-CAGGAGGGCTCACTCAAA-3', antisense: 5'-GATCAGCAGCAAGTCCAGCAG-3'; $\beta$-actin: Sense: 5'-AGCGAGCATCCCCCAAAGTT3', antisense: 5'-GGGCACGAAGGCTCATCATT-3' (Aoke, China).

\subsection{Western blot analysis}

Tca8113 cell lines were treated with nicotine, and wholecell lysates were prepared from treated and untreated control cells. Protein concentration was determined using the Bradford reagent. Equal amounts of protein extracts were analyzed in duplicate by SDS-PAGE. Prx1 polyclonal antibody (1:2000, Abcam, USA), GST $\pi$ polyclonal antibody (1:200, ZSGB-BIO, China) and a monoclonal antibody against $\beta$-actin $(1: 2000$, Santa Cruz, USA). Protein level was detected by an ECL Test Kit and visualized by autoradiography. For normalization of protein loading, the membranes were stripped using stripping buffer and prepared for Western blot analysis with $\beta$-actin antibody as a reference.

\subsection{Immuno-fluorescence}

Tca8113 cells plated at glass coverslips and treated with $1 \mu \mathrm{mol} / \mathrm{L}$ nicotine for 24,48 or $72 \mathrm{~h}$, were washed twice with PBS, and fixed with ice-cold $4 \%$ paraformaldehyde for 10 min. After blocking using 10\% goat serum for $30 \mathrm{~min}$, the cells were incubated with rabbit monoclonal anti-NF$\kappa \mathrm{B}$ primary antibodies $\left(1: 100\right.$, Abcam, USA) at $37^{\circ} \mathrm{C}$ for $1 \mathrm{~h}$, washed 5 times in PBS, stained with conjugated secondary antibody for $1 \mathrm{~h}$ at room temperature in dark, washed 5 times for 5 min with PBS, mount coverslip with anti-fading agent.

\subsection{Statistical analysis}

Data are presented as means \pm standard deviation (SD). Two 
independent $\mathrm{T}$ tests were used to assess differences between control and treated cells. A probability level of $P<0.05$ was considered statistically significant. The analyses were performed with SPSS Software for Windows 11.5.

\section{Results}

\section{$2.1 \quad$ MTT assay}

As shown in Figure 1, the proliferation of Tca8113 cells was increased after treatment with $0.1,1$ or $10 \mu \mathrm{mol} / \mathrm{L}$ nicotine for 24 or $48 \mathrm{~h}(P<0.05)$. However, cell proliferation was reduced after treatment with $100 \mu \mathrm{mol} / \mathrm{L}$ nicotine for $72 \mathrm{~h}$ $(P<0.05)$.

\subsection{ROS assay}

ROS was significantly increased in cells treated with $0.1,1$, 10 , or $100 \mu \mathrm{mol} / \mathrm{L}$ nicotine for $24 \mathrm{~h}$ (Figure 2 ) compared with the untreated cells $(P<0.05)$.

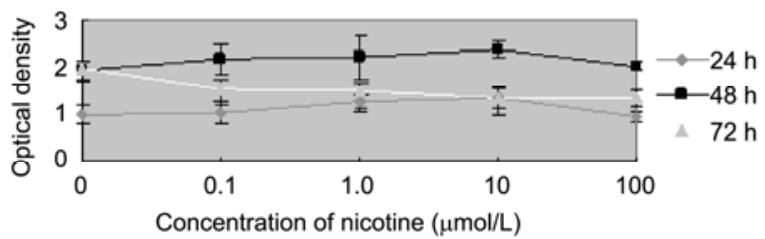

\section{$2.3 \quad$ RT-PCR analysis}

The mRNA expression levels of $\operatorname{Prx} 1$ in Tca8113 cells were shown to be significantly increased by 1.05 -fold $(P<$ $0.05), 1.1$-fold $(P<0.05), 1.1$-fold $(P<0.05)$ and 1.1-fold $(P<$ $0.05)$ in cells treated with $0.1,1,10$ or $100 \mu \mathrm{mol} / \mathrm{L}$ nicotine, respectively, for $48 \mathrm{~h}$, when compared to nicotine-untreated cells (Figure 3(a)). The expression level of Prx 1 in cells treated with $1 \mu \mathrm{mol} / \mathrm{L}$ nicotine for 24,48 or $72 \mathrm{~h}$ was determined. $\operatorname{Prx} 1$ was significantly up-regulated after 48 and $72 \mathrm{~h}$ treatment $(P<0.05)$, but not $24 \mathrm{~h}$ treatment when compared to untreated cells (Figure 3(b)). The mRNA expression levels of GST $\pi$ were shown to be significantly increased by 1.1 -fold $(P<0.05), 1.1$-fold $(P<0.05), 1.1$-fold $(P<0.05)$ in cells treated with $0.1,1,10 \mu \mathrm{mol} / \mathrm{L}$ nicotine, respectively, for $48 \mathrm{~h}$, when compared to nicotine-untreated cells (Figure 4(a)). The expression level of GST $\pi$ was significantly up-regulated $(P<0.05)$ in Tca8113 cells treated with $1 \mu \mathrm{mol} / \mathrm{L}$ nicotine for 24,48 or $72 \mathrm{~h}$ when compared to untreated cells (Figure 4(b)).

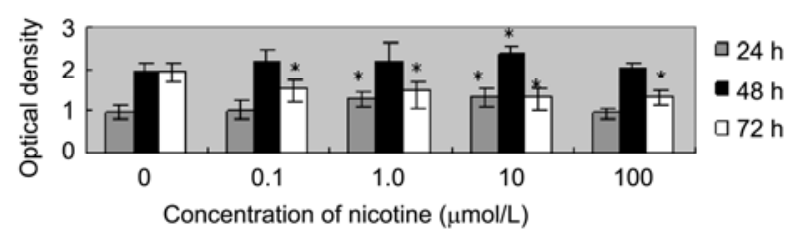

Figure 1 Effects of nicotine on Tca8113 cells. Viability was measured by MTT assay. Columns: average of three independent experiments; error bars: $\pm \mathrm{SD}$; using a two-tailed Student's $t$-test, $* P<0.05$ versus untreated cells.
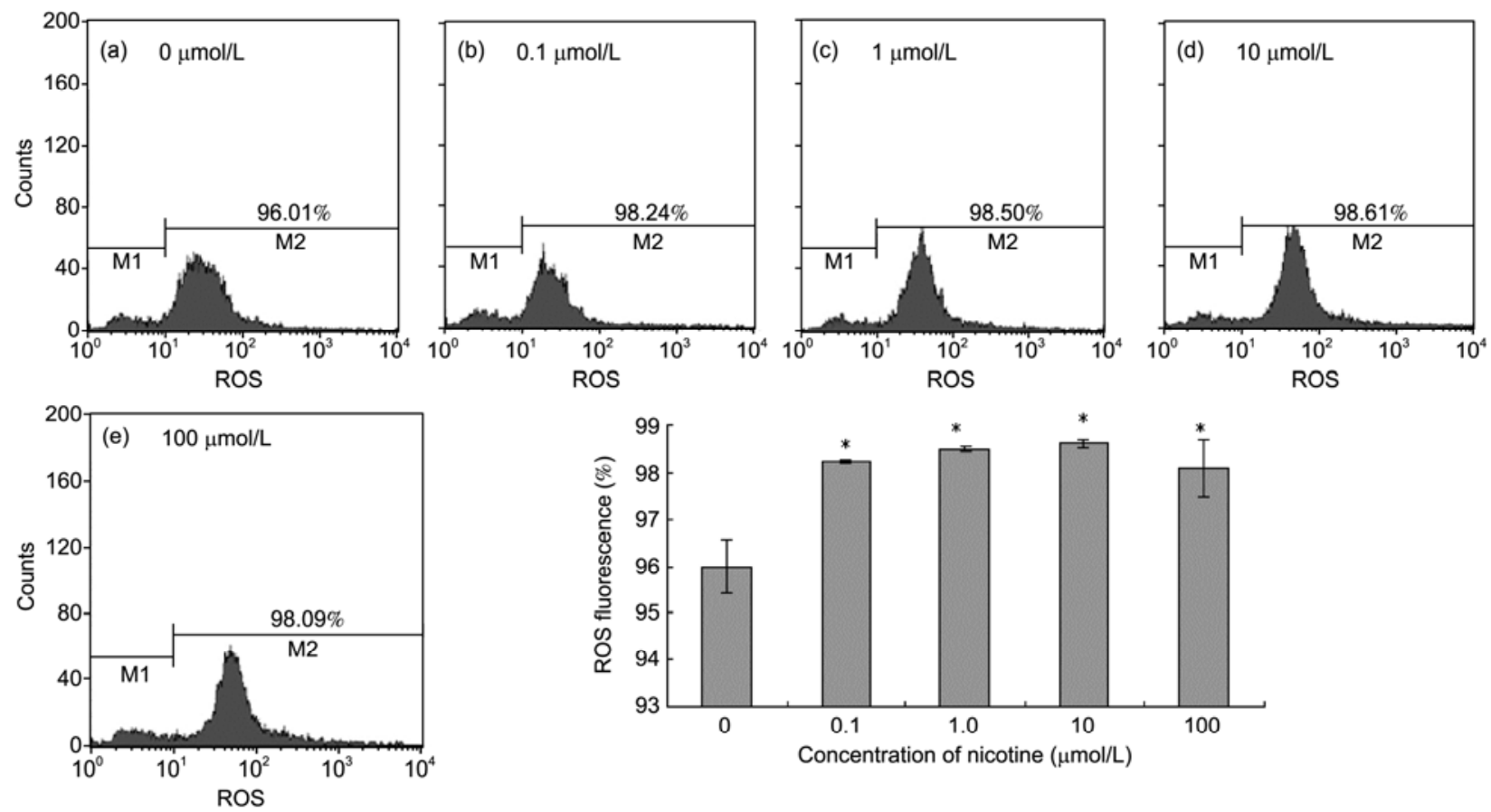

Figure 2 ROS levels detected in Tca8113 cells treated with nicotine for $24 \mathrm{~h}$. Columns: average of three independent experiments; error bars: \pm SD; using a two-tailed Student's $t$-test, * $P<0.05$ versus untreated cells. 
(a)

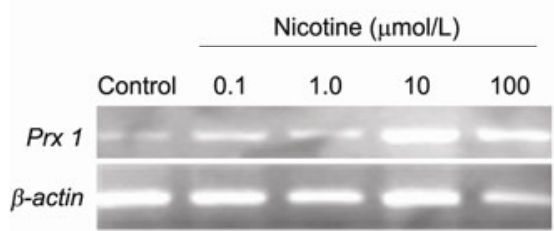

(b)

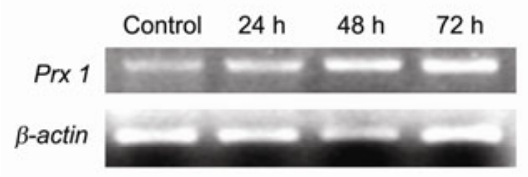

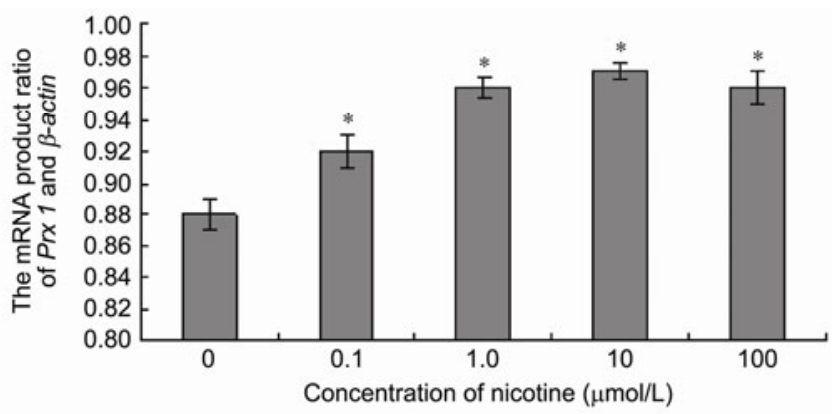

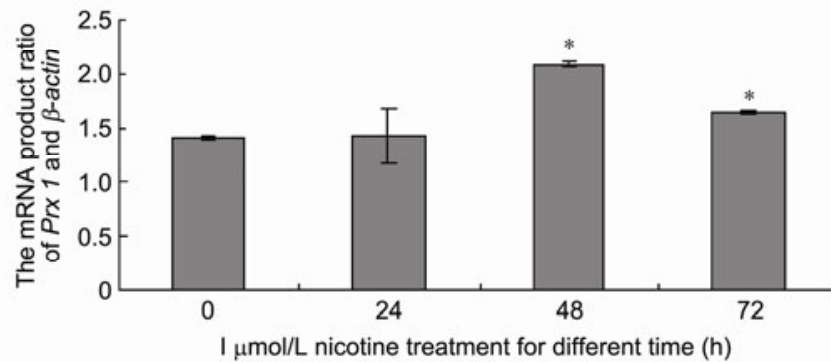

Figure $3 \operatorname{Prx} 1$ mRNA expression assessed by RT-PCR in Tca8113 cells treated with $0.1,1,10$ or $100 \mu \mathrm{mol} / \mathrm{L}$ nicotine for $48 \mathrm{~h}$ (a) and $1 \mu \mathrm{mol} / \mathrm{L}$ nicotine for 24,48 or $72 \mathrm{~h}$ (b). Columns: average of three independent experiments; error bars: \pm SD; using two-tailed Student's $t$-test, * $P<0.05$ versus control group.

\subsection{Western blot analysis}

As depicted in Figure 5(a), the protein expression levels of Prx 1 in Tca8113 cells were significantly increased by 1.3 fold $(P<0.05), 1.8$-fold $(P<0.05), 2.5$-fold $(P<0.05)$ and 2.6-fold $(P<0.05)$ in cells treated with $0.1,1,10$ or 100 $\mu \mathrm{mol} / \mathrm{L}$ nicotine, respectively, for $48 \mathrm{~h}$, when compared to nicotine-untreated cells. The protein expression of Prx 1 in cells treated with $1 \mu \mathrm{mol} / \mathrm{L}$ nicotine for 24,48 and $72 \mathrm{~h}$ was also evaluated. The data show that Prx 1 was significantly increased by 1.4-fold, 1.6-fold and 2.0-fold at 24, 48 and 72 $\mathrm{h}$, respectively, when compared to nicotine-untreated cells $(P<0.05$, Figure 5(b)).

The protein expression levels of GST $\pi$ were significantly increased by 1.1 -fold $(P<0.05), 1.3$-fold $(P<0.05), 1.2$-fold (a)

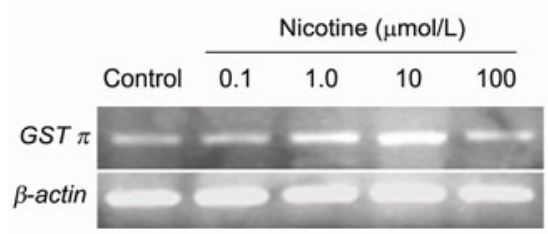

(b)

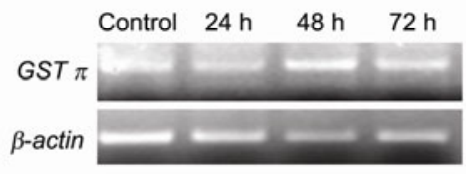

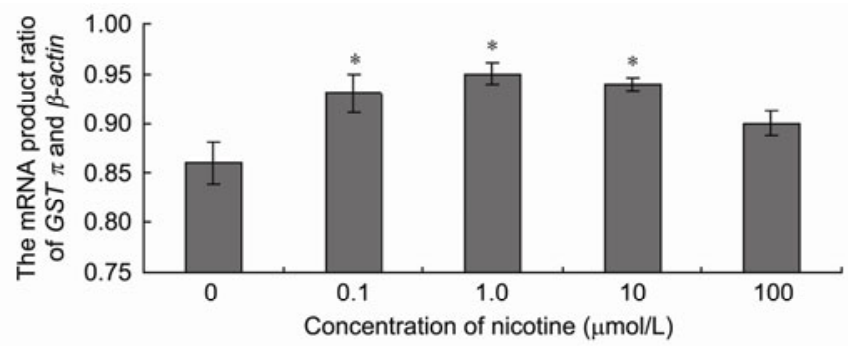

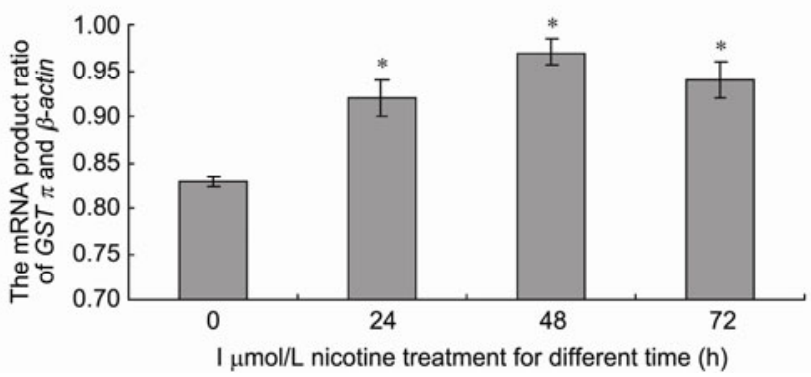

Figure 4 GST $\pi$ mRNA expression assessed by RT-PCR in Tca8113 cells treated with $0.1,1,10$ or $100 \mu \mathrm{mol} / \mathrm{L}$ nicotine for $48 \mathrm{~h}$ (a) and $1 \mu \mathrm{mol} / \mathrm{L}$ nicotine for 24,48 or $72 \mathrm{~h}$ (b). Columns: average of three independent experiments; error bars: \pm SD; using two-tailed Student's $t$-test, $* P<0.05$ versus control group. 
(a)

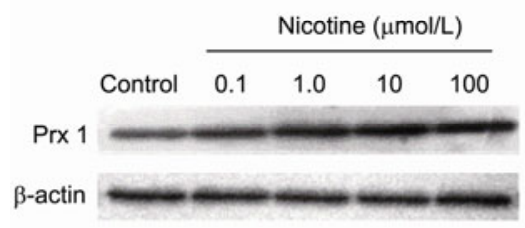

(b)

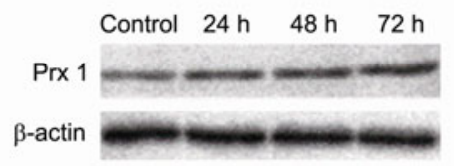

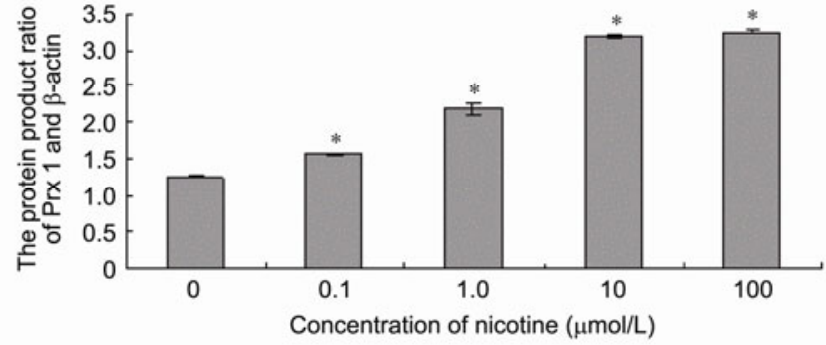

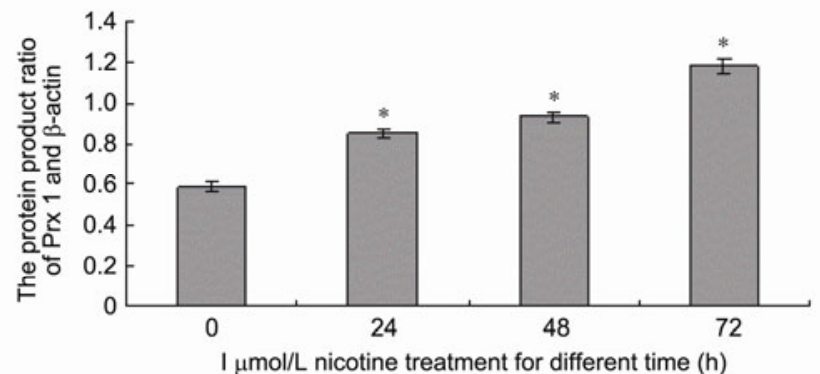

Figure 5 Prx 1 protein expression evaluated by Western blot in Tca8113 cells treated with $0.1,1,10$ or $100 \mu \mathrm{mol} / \mathrm{L}$ nicotine for $48 \mathrm{~h}(\mathrm{a})$ and $1 \mu \mathrm{mol} / \mathrm{L}$ nicotine for 24,48 or $72 \mathrm{~h}$ (b). Membranes were stripped and reprobed with $\beta$-actin as a control. Similar results were obtained from three independent experiments. Columns: mean relative densitometric intensities; error bars: $\pm \mathrm{SD}$; using two-tailed Student's $t$-test, $* P<0.05$ versus control group.

$(P<0.05)$ and 1.5 -fold $(P<0.05)$ in cells treated with $0.1,1$, 10 or $100 \mu \mathrm{mol} / \mathrm{L}$ nicotine, respectively, for $48 \mathrm{~h}$, when compared to nicotine-untreated cells (Figure 6(a)). The data show that the protein expression of GST $\pi$ in cells treated with $1 \mu \mathrm{mol} / \mathrm{L}$ nicotine for 24,48 and $72 \mathrm{~h}$ was significantly increased by 1.1 -fold, 1.3 -fold and 1.8 -fold, respectively, when compared to nicotine-untreated cells $(P<0.05$,
Figure 6(b)).

\subsection{Immuno-fluorescence}

As shown in Figure 7, NF- $\kappa \mathrm{B}$ expression in the nucleus treated with $1 \mu \mathrm{mol} / \mathrm{L}$ nicotine for 24,48 and $72 \mathrm{~h}$ were increased significantly in Tca8113 cells compared to nicotine- (a)

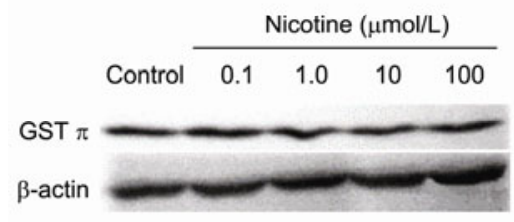

(b)

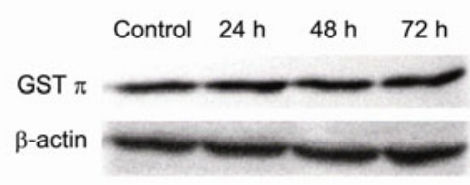

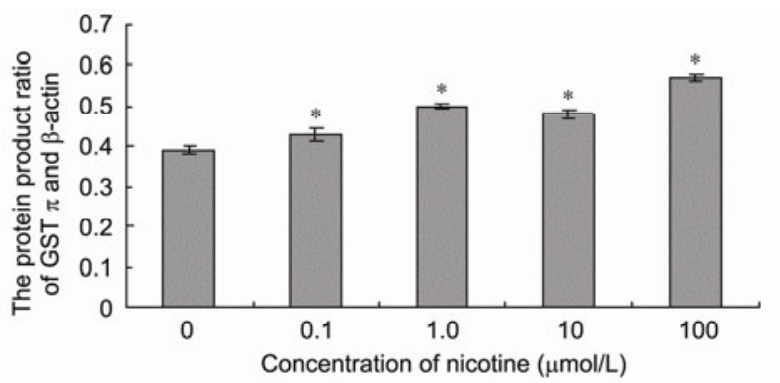

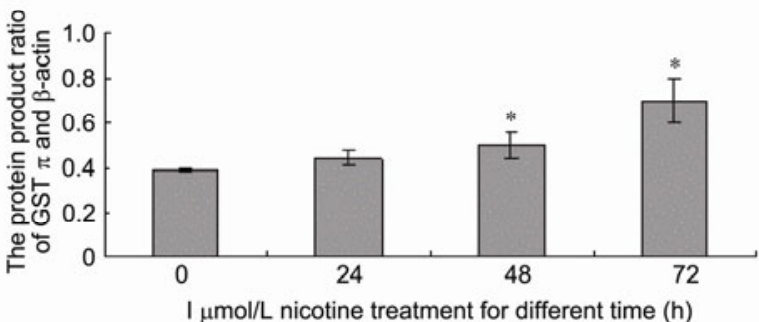

Figure 6 GST $\pi$ protein expression evaluated by Western blot in Tca8113 cells treated with $0.1,1,10$ or $100 \mu$ mol/L nicotine for $48 \mathrm{~h}$ (a) and $1 \mu$ mol/L nicotine for 24,48 or $72 \mathrm{~h}$ (b). Membranes were stripped and reprobed with $\beta$-actin as a control. Similar results were obtained from three independent experiments. Columns: mean relative densitometric intensities; error bars: $\pm \mathrm{SD}$; using two-tailed Student's $t$-test, $* P<0.05$ versus control group. 

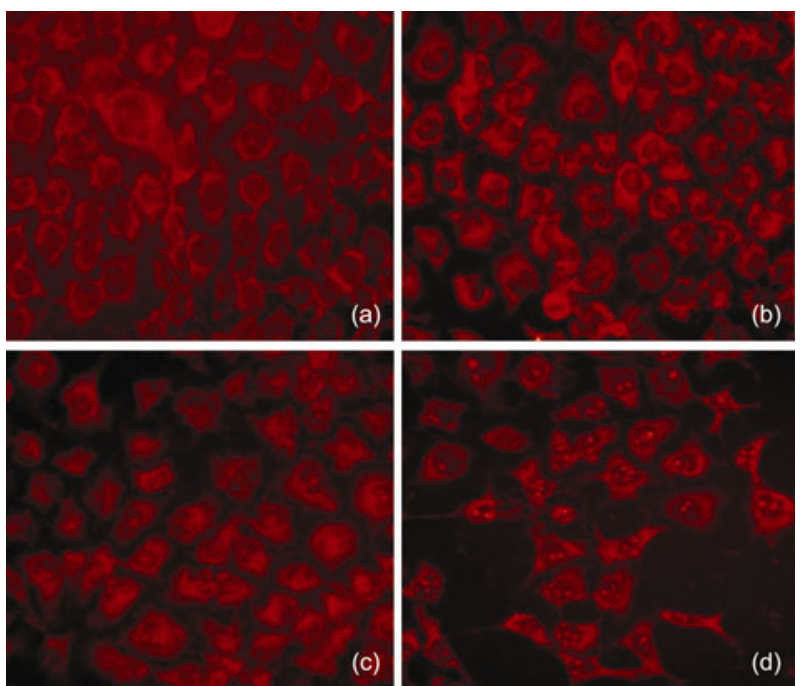

Figure $7 \mathrm{NF}-\kappa \mathrm{B}$ expression in the nucleus treated with $1 \mu \mathrm{mol} / \mathrm{L}$ nicotine for $24 \mathrm{~h} \mathrm{(b),} 48 \mathrm{~h}$ (c) and $72 \mathrm{~h}$ (d) were increased significantly in Tca8113 cells compared to nicotine-untreated cells (a), which indicated that NF- $\kappa B$ was activated and translocated from cytoplasm to nucleus.

untreated cells, which indicated that NF- $\mathrm{BB}$ was activated and translocated from cytoplasm to nucleus.

\section{Discussion}

Epidemiologic studies have shown that tobacco is the primary etiological factor of OSCC [17]. Nicotine, as a source of exogenous oxidative stress, can elevate ROS level and cause DNA strand breakage, protein cross-linking, and lipid peroxidation, which can induce cell oxidative damage and promote oncogenesis [18]. Cultures of human gingival fibroblasts exposed to nicotine exhibited an increase in ROSinduced oxidative stress and conferred protection against DNA injury by the antioxidants NAC and CAT. In the current study, both ROS levels and expression of Prx 1 were increased after nicotine treatment of a human OSCC cell line indicating that Prx 1 may play an important role in tobacco-associated OSCC. An increase in oxidative stress was also observed in colon cancer cells, after exposure to nicotine [16].

Excessive ROS may result in oxidative stress leading to DNA injury, the formation of hydroperoxides from cell membrane phospholipids plays a key role in cellular damage resulting from the action of ROS [19-21]. The Prx gene family plays an antioxidant role through their peroxidase activity removing extra hydrogen peroxide and organic hydroperoxides [22]. Prxs are thiol-specific antioxidant enzymes, a major common function of which is the degradation of hydrogen peroxide to remove extra ROS [23]. Prx 1 which is the most abundant and ubiquitous Prx, plays an important role in protecting cells against oxidants [24]. Other studies have shown that Prx 1 is overly expressed in numerous human malignant tumors including lung, breast, and pancreatic cancers. Yanagawa et al. [25] found that Prx 1 was overly expressed in $79 \%$ of the OSCC specimens examined by immunohistochemistry, whereas Neumann et al. [26] reported that overexpression of Prx 1 was associated with oxidative stress.

$\mathrm{NF}-\kappa \mathrm{B}$ is a nucleus transcription factor which plays important roles in a number of pathological conditions, for example oxidative stress. The activity of $\mathrm{NF}-\kappa \mathrm{B}$ is primarily regulated by interaction with inhibitory $\mathrm{I} \kappa \mathrm{B}$ proteins. In most cells, NF- $\kappa \mathrm{B}$ is present as a latent, inactive, I $\kappa \mathrm{B}$-bound complex in the cytoplasm. When a cell is stimulated NF- $\kappa \mathrm{B}$ rapidly enters the nucleus and activates downstream gene expression [27]. In oxidative stress, ROS have various inhibitory or stimulatory roles in $\mathrm{NF}-\kappa \mathrm{B}$ signaling. NF- $\mathrm{NB}$ plays a major role in regulating the amount of ROS in the cell and regulates downstream transcriptional antioxidant and pro-oxidant targets [28]. One of the most important ways in which NF- $\kappa \mathrm{B}$ activity influences ROS levels is via increased expression of antioxidant proteins. Crosstalk from $\mathrm{NF}-\kappa \mathrm{B}$ to JNK is known to prevent sustained JNK activation and thus prevents cell death through both apoptosis and necrosis [29]. GST $\pi$ is up-regulated by oxidative stress through NF- $\kappa$ B. GST $\pi$ is a phase II enzyme that catalyzes the reaction of the GSH thiolate to toxic electrophilic compounds, eliminate ROS or reactive carcinogens by excretion machinery. It is also proposed to repair the damage from oxidative stress. Disruption of the gene encoding GST $\pi$ in HCT116 cells showed that GSTP1 protects HCT116 cells from oxidative stress and resultant apoptosis under growthlimiting conditions [12].

Radiation-induced cytotoxicity is mediated primarily by the generation of ROS and ROS-driven oxidative stress. Prx 1 exhibits a protective effect in tumor cells through enhancing clonogenic survival of irradiated cells against oxidative stress in lung cancer [30]. Overexpression of Prx 1 enhances the clonogenic survival of irradiated cells and suppresses ionizing radiation-induced JNK activation and apoptosis. The peroxidase activity of Prx 1, however, is not essential for inhibiting JNK activation. The latter effect is mediated through its interaction with the GST $\pi$-JNK complex, thereby preventing JNK release from the complex [10].

In our previous studies, we observed an up-regulation of Prx 1 and GST $\pi$ in Tca8113 cells when compared to an oral precancerous cell line, DOK, by DNA microarray and immunohistochemistry [13]. In the current investigation, both mRNA and protein expression of Prx 1 and GST $\pi$ were induced by nicotine in Tca8113 cells. A possible mechanism leading to Prx 1 and GST $\pi$ over-expression is likely due to the induction of ROS by nicotine. NF- $\kappa \mathrm{B}$ expression increased in Tca8113 cell nucleus treated with $1 \mu \mathrm{mol} / \mathrm{L}$ nicotine indicates that NF- $\kappa \mathrm{B}$ is activated by nicotine induced oxidative stress, translocates from cytoplasm to nucleus, interactes with Prx 1 which is overexpressed in nu- 
cleus and makes downstream transcriptional pathway activation, thereby regulates cell proliferation and apoptosis. The results suggest that $\operatorname{Prx} 1$ is associated with tobacco-induced oxidative stress involved in OSCC and may serve as a new biomarker in OSCC. All findings might enable the development of new, more targeted approaches to treatment of oral cancers.

This work was supported by the Beijing Natural Science Foundation (7102065) and the National Natural Science Foundation of China (81070836).

1 Jemal A, Bray F, Center M M, et al. Global cancer statistics. CA Cancer J Clin, 2011, 61: 69-90

2 Wu J Y, Yi C, Chung H R, et al. Potential biomarkers in saliva for oral squamous cell carcinoma. Oral Oncol, 2010, 46: 226-231

3 Moral M, Segrelles C, Lara M F, et al. Akt activation synergizes with Trp53 loss in oral epithelium to produce a novel mouse model for head and neck squamous cell carcinoma. Cancer Res, 2009, 69: 1099-1108

4 Scully C, Bagan J. Oral squamous cell carcinoma overview. Oral Oncol, 2009, 45: 301-308

5 Macha M A, Matta A, Chauhan S S, et al. Guggulsterone (GS) inhibits smokeless tobacco and nicotine-induced NF- $\mathrm{BB}$ and STAT3 pathways in head and neck cancer cells. Carcinogenesis, 2011, 32: 368380

6 Oda D, Nguyen M P, Poyack G A, et al. $\mathrm{H}_{2} \mathrm{O}_{2}$ oxidative damage in cultured oral epithelial cells: The effect of short-term vitamin $\mathrm{C}$ exposure. Anticancer Res, 2001, 21: 2719-2724

7 Wu H J, Chi C W, Lin T Y. Effects of PH on nicotine-induced DNA damage and oxidative stress. J Toxicol Environ Health A, 2005, 68: $1511-1523$

8 Robinson M W, Hutchinson A T, Dalton J P, et al. Peroxiredoxin: A central player in immune modulation. Parasite Immunol, 2010, 32: 305-313

9 Kim Y J, Ahn J Y, Liang P, et al. Human Prx1 gene is a target Nrf2 and is up-regulated by hypoxia/reoxygenation: Implication to tumor biology. Cancer Res, 2007, 67: 546-554

10 Kim Y J, Lee W S, Ip C, et al. Prx1 suppresses radiation-induced c-Jun $\mathrm{NH}_{2}$-terminal kinase signaling in lung cancer cells through interaction with the glutathione S-transferase $\mathrm{Pi} / \mathrm{c}$-Jun $\mathrm{NH}_{2}$-terminal kinase complex. Cancer Res, 2006, 66: 7136-7142

11 Yanagawa T, Omura K, Harada H, et al. Peroxiredoxin1 expression in tongue squamous cell carcinoma as involved in tumor recurrence. Int J Oral Maxilllofac Surg, 2005, 34: 915-920

12 Townsend D M, Manevich Y, He L, et al. Novel role for glutathione S-transferase pi. Regulator of protein S-glutathionylation following oxidative and nitrosative stress. J Biol Chem, 2009, 284: 436-545
13 Tang X F, Zhang X Y, Zhang M, et al. Differential gene expression related to oxidative stress in oral cancer and oral precancerous lesion cells (in Chinese). Beijing J Stomatol, 2008, 16: 308-311

14 Drigo I, Piscianz E, Valencic E, et al. Selective resistance to different glucocorticoids in severe autoimmune disorders. Clin Immunol, 2010, 134: $313-319$

15 Rajendra P N, Karthikeyan A, Karthikeyan S, et al. Inhibitory effect of caffeic acid on cancer cell proliferation by oxidative mechanism in human HT-1080 fibrosarcoma cell line. Mol Cell Biochem, 2011, 349: 11-19

16 Crowley-Weber C L, Dvorakova K, Crowley C, et al. Nicotine increases oxidative stress, activates NF- $\mathrm{KB}$ and GRP78, induces apoptosis and sensitizes cells to genotoxic/xenobiotic stresses by a multiple stress inducer, deoxycholate: Relevance to colon carcinogenesis. ChemBio Interact, 2003, 145: 53-66

17 Schottenfeld D. The etiology and prevention of aerodigestive tract cancers. Adv Exp Med Biol, 1992, 320: 1-19

18 Jayalekshmi P A, Gangadharan P, Akiba S, et al. Tobacco chewing and female oral cavity cancer risk in Karunagappally cohort, India. Br J Cancer, 2009, 100: 848-852

19 Miguel F, Augusto A C, Gurgueira S A. Effect of acute vs chronic $\mathrm{H}_{2} \mathrm{O}_{2}$-induced oxidative stress on antioxidant enzyme activities. Free Radic Res, 2009, 43: 340-347

20 Yan F, Mu Y, Yan G L, et al. Antioxidant enzyme mimics with synergism. Mini Rev Med Chem, 2010, 10: 342-356

21 Cadet J, Douki T, Ravanat J L. Oxidatively generated base damage to cellular DNA. Free Radic Biol Med, 2010, 49: 9-21

22 Park J W, Piszczek G, Rhee S G, et al. Glutathionylation of peroxiredoxin I induces decamer to dimers dissociation with concomitant loss of chaperone activity. Biochemistry, 2011, 50: 3204-3210

23 Cox A G, Winterbourn C C, Hampton M B. Mitochondrial peroxiredoxin involvement in antioxidant defence and redox signalling. Biochem J, 2009, 425: 313-325

24 Ishii T, Yanagawa T. Stress-induced peroxiredoxins. Subcell Biochem, 2007, 44: 375-384

25 Yanagawa $\mathrm{T}$, Iwasa $\mathrm{S}$, Ishii $\mathrm{T}$, et al. Peroxiredoxin1 expression in oral cancer: A potential new tumor marker. Cancer Lett, 2000, 156: 27-35

26 Neumann C A, Krause D S, Carman C V, et al. Essential role for the peroxiredoxin Prdx1 in erythrocyte antioxidant defence and tumour suppression. Nature, 2003, 424: 561-565

27 Kabe Y, Ando K, Hirao S, et al. Redox regulation of NF- $\kappa$ B activation: Distinct redox regulation between the cytoplasm and the nucleus. Antioxid Redox Signal, 2005, 7: 395-403

28 Morgan M J, Liu Z G. Crosstalk of reactive oxygen species and NF- $\kappa$ B signaling. Cell Res, 2011, 21: 103-115

29 Bubici C, Papa S, Pham C G, et al. The NF-kappaB-mediated control of ROS and JNK signaling. Histol Histopathol, 2006, 21: 69-80

30 Lee $\mathrm{S}$ B, Ho J N, Yoon S H, et al. Peroxiredoxin 6 promotes lung cancer cell invasion by inducing urokinase-type plasminogen activator via p38 kinase, phosphoinositide 3-kinase, and Akt. Mol Cells, 2009, 28: 583-588

Open Access This article is distributed under the terms of the Creative Commons Attribution License which permits any use, distribution, and reproduction in any medium, provided the original author(s) and source are credited. 